\title{
- Artrite Encefalite Caprina - aspectos clínicos e epidemiológicos
}

\section{- Caprine Arthritis-Encephalites - clinical and epidemiological aspects}

Universidade de Santo Amaro - UNISA.

Rua Professor Eneas de Siqueira Neto, 340 Jardim das Imbúias CEP:04829-300 São Paulo - SP.

\section{RESUMO}

Apresenta-se uma revisão da Artrite Encefalite Caprina, enfatizando os aspectos clínicos e epidemiológicos da doença, sugerindo medidas de controle com vistas a prevenir o avanço desta enfermidade nos rebanhos caprinos.

Unitermos: artrite encefalite caprina, AEC, aspectos clínicos, epidemiologia

\section{Introdução}

A Artrite Encefalite Caprina (AEC) é uma doença infecciosa, multissistêmica, causada por um retrovírus do gênero Lentivirus, que acomete caprinos de todas as idades. Descrita, pela primeira vez, por CORK et al $(1974)^{7}$, em cabritos de 1 a 4 meses de idade infectados natural e experimentalmente, é caracterizada por sua natureza crônica de aspecto insidioso, tendo como principais manifestações clínicas uma leucoencefalomielite, que acomete cabritos ${ }^{7}$, e, artrite, mais freqüente nos animais adultos 9 .

\section{Etiopatogenia}

O agente da AEC é um RNA vírus, da Família Retroviridae, gênero Lentivirus, que engloba, entre outros, o vírus da Anemia Infecciosa Eqüina (AIE) e o vírus da Pneumonia Ovina Progressiva / Maedi-Visna (OPP/MV), que apresenta similaridades antigênicas com o vírus da $\mathrm{AEC}^{5}$.

$\mathrm{O}$ vírus da AEC infecta as células do sistema mononuclear-fagocitário, resultando na produção de anticor- pos contra as proteínas do núcleo e as glicoproteínas do envelope viral ${ }^{12}$. Este agente é sensível ao calor e à maioria dos desinfetantes químicos 22 .

$\mathrm{O}$ ciclo de vida desse vírus inicia-se com a ligação ao receptor da célula do hospedeiro, penetração no citoplasma da célula-alvo e a perda do envelope glicoprotéico. Este processo libera o ácido nucleico viral, dando início à replicação do vírus ${ }^{17}$. Uma agressão ao organismo leva à passagem de monócitos infectados para a circulação e a contaminação das células dos órgãosalvo destes vírus, determinando a resposta imune do hospedeiro e as lesões de encefalite, artrite e sinovi$t^{21,23}$.

\section{Epidemiologia}

A AEC é cosmopolita, e o primeiro levantamento sorológico foi realizado em 1981, por CRAWFORD e ADAMS $^{8}$. Posteriormente, ADAMS et al., avaliaram 3729 amostras de soro, provenientes de 14 países, e concluíram que o vírus se originou na Europa, tendo chegado aos outros continentes pela importação de animais ${ }^{2}$. O Quadro 1 sumariza os resultados encontra- 
Quadro 1 - Frequência de ocorrência e total de amostras de caprinos avaliadas para CAE pela prova de IDAG, em diversos países e anos, por diferentes autores apud4

\begin{tabular}{|l|l|l|r|r|}
\hline AUTOR & ANO & PAís & $\%$ & TOTAL \\
\hline Crawford e Adams & 1981 & EUA & 81,0 & 1160 \\
Straub & 1983 & Alemanha & 31,5 & 73 \\
Adams et al. & 1984 & vários & 33,9 & 3729 \\
Dawson e Wilesmith & 1985 & Inglaterra & 4,3 & 2792 \\
Agrimi et al. & 1985 & Itália & 74,0 & 198 \\
Nazara et al. & 1985 & México & 27,0 & 857 \\
Grewal & 1986 & Austrália & 56,7 & 2708 \\
Perrin e Polack & 1987 & França & 13,4 & 3063 \\
Truyen et al. & 1991 & Alemanha & 310 & 379 \\
Gutlip et al. & 1992 & EUA & 3790 \\
\hline
\end{tabular}

dos por diversos autores que estudaram a frequiência de ocorrência da $\mathrm{AEC}$ em várias partes do mundo.

No Brasil, a AEC tem sido descrita em vários Estados brasileiros, como pode-se observar no Quadro 2. Em São Paulo, a ocorrência da AEC foi demonstrada pela primeira vez, por GARCIA et al. ${ }^{16}$, em 1992. No mesmo ano, no Rio Grande do Sul, o vírus da AEC foi isolado a partir de culturas de membrana sinovial de caprinos com artrite e sororreagentes ${ }^{18}$. Em 1997, FERNANDES determinou a taxa de prevalência da doença no Estado de São Paulo ${ }^{14}$.

A transmissão da doença ocorre pela ingestão de colostro e leite contaminados pelo vírus da $\mathrm{AEC}^{1,8,13,28}$, e pelo contato entre os animais, propiciando a contaminação por meio de secreções urogenitais, saliva, fezes, secreções do trato respiratório, ordenhadeira, mãos, toalhas e outros fômites contaminados ${ }^{1,29}$. A transmissão intra-uterina ou pelo sêmen contaminado, não parecem assumir um papel de importância na disseminação da doença ${ }^{1,29}$.

\section{Sintomas e Lesões}

Os principais sintomas e lesões da AEC estão localizados nas articulações, glândula mamária, sistema nervoso e pulmões ${ }^{33}$.

De aparecimento insidioso ou repentino a artrite é o sintoma mais freqüente da doença, acometendo preferencialmente os animais adultos, entre 2 e 9 anos de idade $^{9,22}$. Todas as articulações podem ser afetadas, mas o sítio preferido da lesão é a articulação carpometacarpiana $8,33,34$. Os animais apresentam claudicação, dor e aumento de volume articular ${ }^{8}$, podendo ainda ser observado aumento de linfonodos regionais e higroma carpal ${ }^{34}$. Com a progressão da artrite, há restrição da movimentação articular e desvios do terço distal do membro. Os animais severamente afetados podem permanecer em decúbito por longos períodos levando a dermatites, ulceração, abscedação e osteomielites ${ }^{8}$. Outros sinais incluem emagrecimento, pêlos longos, ásperos e quebradiços, mas, a despeito da condição corpórea não há febre, estando os animais alerta e com apetite 22 .

$\mathrm{Na}$ fase aguda da doença o líquido sinovial apresenta-se amarronzado ou avermelhado, com volume variável, diminuição da viscosidade e aumento da celularidade (1.000-20.000 células por $\left.\mathrm{mm}^{3}\right)$, principalmente mononucleares (linfócitos). Na fase crônica, a coloração é clara, o volume normal e a celularidade é baixa (100500 células por $\left.\mathrm{mm}^{3}\right)^{8,34}$.

Radiograficamente, encontram-se reações ósseas periosteais, com produção de osteofitos peri-articulares, mineralização periarticular, degeneração articular e superfícies articulares irregulares 8,34 .

Podendo ou não estar associada à artrite, a forma mamária da doença tem importância econômica ${ }^{4}$. De maneira geral, o vírus da AEC causa uma mastite catarral incipiente, sem alterações ao exame físico do leite, porém, com aumento de células somáticas ${ }^{25,30}$. A glândula mamária apresenta-se mais firme à palpação podendo haver queda na produção leiteira de leve a moderada, ou agalaxia ${ }^{12}$. Logo após o parto, pode ocorrer um endurecimento difuso da glândula mamária, com úbere firme à palpação, ordenha pouco produtiva ou agalaxia $\mathrm{e}$ aumento de volume dos linfonodos retromamários ${ }^{27}$. A presença do vírus da AEC na glândula mamária pode aumentar a susceptibilidade à infeção bacteriana ${ }^{30}$. 
BOHLAND, E.; D’ANGElino, J. L. Artrite Encefalite Caprina - aspectos clínicos e epidemiológicos. Revista de Educação Continuada do CRMV-SP / Continuous Education Journal CRMV-SP, São Paulo, volume 2, fascículo 2, p. 004 - 008, 1999.

Quadro 2 - Ocorrência da CAE no Brasil em vários estados e anos, por diferentes autores

\begin{tabular}{|l|l|l|r|r|}
\hline AUTOR & ANO & ESTADO & $\%$ & TOTAL \\
\hline Moojen et al.19 & 1986 & RS & 4,0 & 67 \\
Fitterman e Gillet14 & 1988 & BA & 12,0 & 13 \\
Garcia et al. ${ }^{15}$ & 1992 & SP & 49,0 & 125 \\
D'Angelino et al.10 & 1993 & SP & 37,5 & 873 \\
Saraiva Neto et al.10 & 1994 & PE & 17,6 & 397 \\
Assis e Gouveia3 & 1994 & MG, RJ, BA, CE & 28,8 & 1601 \\
Cunha e Nascimento9 & 1995 & RJ & 21,1 & 242 \\
Pinheiro et al. 25 & 1996 & PI & 4,4 & 180 \\
Fernandes ${ }^{13}$ & 1997 & SP & 29,8 & 2065 \\
\hline
\end{tabular}

Histologicamente, as lesões no tecido mamário constituem-se por acúmulos de mononucleares (principalmente linfócitos, macrófagos) no parênquima mamário e ao redor dos ácinos tubulares, associada a uma linfadenite subaguda ou crônica dos linfonodos retromamários ${ }^{19}$.

A leucoencefalomielite acomete preferencialmente cabritos menores de 4 meses $7,8,22$, sendo caracterizada por uma paresia ou ataxia de membros posteriores, uni ou bilateral, tetraparesia, decúbito seguido de morte ou a realização do sacrifício dos doentes. Os animais que sobrevivem apresentam uma paralisia residual, torcicolo e desvios da cabeça e pescoço 7,22 . Outros sinais são pêlos ásperos e secos, um menor desenvolvimento corpóreo e atrofia muscular dos membros paralisados 6 . O exame do líquido cefalorraquidiano revela um aumento do número de leucócitos em sua maioria linfócitos, poiquilocitose e presença de hemácias ${ }^{8}$.

À necrópsia, encontram-se lesões de atrofia de membros posteriores ${ }^{7}$ e lesões ocasionais na medula espinhal e em alguns sítios do cérebro ${ }^{6}$. Microscopicamente, ocorre desmielinização perivenosa e acúmulo de células linforeticulares na substância branca. Lesões de áreas mielinizadas, espalhadas no cérebro e medula espinhal, são creditadas por causarem a maioria dos sinais clínicos ${ }^{6}$.

Outro achado clínico é uma pneumonia crônica intersticial que pode ocorrer tanto em adultos ${ }^{34}$ como em jovens ${ }^{6}$. Esse quadro caracteriza-se por presença de dispnéia, tosse, secreção nasal, perda da condição corpórea $\mathrm{e}$, à auscultação dos pulmões, nota-se a presença de estertores 24,32 .

Macroscopicamente podem ser visualizadas aderências pleurais, áreas de hepatização, congestão, ede- ma e atelectasia, e microscopicamente observam-se espessamento da pleura e de septos interalveolares, com infiltração linfocitária difusa e perivascular ${ }^{32}$, e hiperplasia linfóide pronunciada ${ }^{7}$.

\section{Diagnóstico}

Após a exposição ao agente da $\mathrm{AEC}$, os animais tornam-se persistentemente infectados, mas nem sempre apresentam alterações evidentes ao exame clínico. Desta forma, é necessária a realização do exame sorológico para identificar a presença de anticorpos reagentes ao vírus da $\mathrm{AEC}^{8}$. A prova de imunodifusão em ágar gel é o teste sorológico mais utilizado no mundo para verificar a ocorrência da doença ${ }^{2}$. Outras provas sorológicas utilizadas são o ensaio imunoenzimático, radioimunoensaio e immunoblotting.

Apesar das evidências clínicas e anatomopatológicas, é necessário que se estabeleça o diagnóstico diferencial da AEC em relação a outras enfermidades. A leucoencefalomielite deve ser diferenciada da doença do músculo branco, traumatismos, listeriose, polioencefalomalácia, toxoplasmose e deficiência de cobre $^{6}$. A artrite deve ser diferenciada de qualquer causa traumática, metabólica ou infecciosa. Além disso, podem ocorrer processos concomitantes à artrite por AEC causados por micoplasma, clamídia ou outras bactérias ${ }^{33}$.

\section{Controle}

Diante da inexistência de tratamento da AEC, as medidas de controle são fundamentais para prevenir o avanço da doença nos rebanhos caprinos. Os programas 
BOHLAND, E.; D’ANGELINO, J. L. Artrite Encefalite Caprina - aspectos clínicos e epidemiológicos. Revista de Educação Continuada do CRMV-SP / Continuous Education Journal CRMV-SP, São Paulo, volume 2, fascículo 2, p. 004 - 008, 1999.

de controle estão baseados na prevenção das várias formas de transmissão ou seja, evitando a transmissão pelo colostro e leite, o contato direto entre os animais e acompanhando a eficácia dessas medidas mediante testes sorológicos periódicos.

Desta forma, recomenda-se a remoção das crias de suas mães imediatamente após o nascimento; fornecimento às crias de colostro de cabra pasteurizado a $56^{\circ} \mathrm{C}$ por uma hora ou colostro de vaca; aleitamento das crias com leite de cabras não infectadas, leite de vaca pasteurizado ou leite de cabra infectada pasteurizado $^{1}$; realização de testes sorológicos a cada 6 meses (no mínimo) em todos os animais do rebanho, separando os positivos dos negativos $21,28,33$; evitar fatores que propiciem a disseminação da doença dentro do criatório como superlotação e contaminação de alimentos, água, equipamentos e pessoal, com secreções de animais positivos $^{28}$; estabelecimento de linha de ordenha, deixando por último os animais infectados ${ }^{33}$; evitar a introdu- ção de animais novos no criatório ${ }^{21}$, ou então procederse a realização de teste sorológico e quarentena antes de introduzi-los ao rebanho ${ }^{33}$; utilização de bodes ou sêmen de animais negativos na reprodução ${ }^{21}$; evitar compartilhar o uso de agulhas, seringas, tatuadores, instrumentos cirúrgicos e outros fômites sem prévia desinfecção ${ }^{33}$; nos rebanhos de baixa prevalência, sacrificar os animais positivos ${ }^{33}$.

Estas medidas são fundamentais para prevenir o avanço da doença nos rebanhos caprinos. Entretanto, devemos lembrar as dificuldades que o criador encontra para realizá-las. De um lado, pelo trabalho que elas exigem, principalmente em grandes rebanhos leiteiros comerciais, onde nem sempre há mão de obra qualificada, ou instalações adequadas para que estas possam ser tomadas de maneira efetiva. De outro lado, estão os problemas relacionados com a realização de testes periódicos nos animais pelas dificuldades de se manter um serviço permanente de diagnóstico da AEC à disposição dos criadores.

\section{SUMMARY}

A review on caprine arthritis-encephalites (CAE) is presented. Clinical, epidemiological aspects as well control procedures in order to prevent the progression of the disease in goat herds are described.

Uniterms: caprine arthritis-encephalitis, CAE, clinical signs, epidemiology.

\section{REFERÊNCIAS BIBLIOGRÁFICAS}

1 - ADAMS, D. S.; KLEVJER-ANDERSON, P.; CARLSON, J. L.; MC GUIRE, T. C.; GORHAM, J. R. Transmission and control of caprine arthritis-encephalitis virus. American Journal Veterinary Research, v.44, n.9, p.1670-5, 1983.

2 - ADAMS, D. S.; OLIVER, R. E.; AMEGGHINO, E.; DEMARTINI, J. C.; VERWOERD, D. W.; HOWERS, D. J.; WAGHELA, S.; GORHAM, J. R.; HYLSETH, B.; DAWSON, M.; TRIGO, F. J.; McGUIRE, T. C. Global survey of serological evidence of caprine arthritis-encephalitis virus infection. Veterinary Record, v.115, n.19, p.493-5, 1984.

3 - ASSIS, A. P. M. V.; GOUVEIA, A. M. G. Evidências sorológicas de lentivirus (maedi visna/ artrite encefalite caprina) em rebanhos nos Estados de MG., RJ., BA, CE. In: CONGRESSO BRASILEIRO DE MEDICINA VETERINÁRIA, 23, Olinda, 1994. Anais. Olinda: Sociedade Pernambucana de Medicina Veterinária, 1994. p.104.

4 - BOHLAND, E. Artrite encefalite caprina: avaliação dos aspectos produtivos e reprodutivos de animais infectados e não infectados. São Paulo. 1998. 95p. Dissertação (Mestrado) - Faculdade de Medicina Veterinária e Zootecnia. Universidade de São Paulo.
5 - COFFIN, J. M.; ESSEX, M.; GALLO, R.; GRAF, T. M.; HINUMA, Y.; HUNTER, E.; JAENISCH, R.; NUSSE, R.; OROSZLAN, S.; SVOBODA, J.; TEICH, N.; TOYOSHIMA, K.; VARMUS, H. ICTV report: Cornelia BüchenOsmond, 1995, last update: 8 april 1998. (On line, 13 de julho de 1998, http://life.anu.edu.au/viruses/Ictv/ fs_retro.ht).

6 - CORK, L. C. Differential diagnosis of viral leukoencephalomyelitis of goats, Journal of American Veterinary Medical Association, v. 19, n. 12, p.1303-6, 1976.

7 - CORK, L. C.; HADLOW, W. J.; CRAWFORD, T. B.; GORHAM, J. R.; PIPER, R. C. Infectious leukoencephalomyelitis of young goats. Journal of Infectious Diseases, v.129, n.2, p.134-41, 1974.

8 - CRAWFORD, T. B.; ADAMS, D. S. Caprine arthritis-encephalitis: clinical features and presence of antibody in selected goat populations. Journal of American Veterinary Association, v.178, n.7, p.713-9, 1981.

9 - CRAWFORD, T. B.; ADAMS, D. S.; CHEEVERS, W. P. Chronic arthritis in goats caused by a retrovirus. Science, v.207, n.29, p.997-9, 1980. 
BOHLAND, E.; D'ANGElino, J. L. Artrite Encefalite Caprina - aspectos clínicos e epidemiológicos. Revista de Educação Continuada do CRMV-SP / Continuous Education Journal CRMV-SP, São Paulo, volume 2, fascículo 2, p.004 - 008, 1999.

10 - CUNHA, R. G.; NASCIMENTO, M. D. Ocorrência de anticorpos para o vírus da artrite encefalite caprina em soros de caprinos do Estado do Rio de Janeiro. Revista Brasileira de Medicina Veterinária, v.17, n.2, p.72-5, 1995.

11 - D'ANGELINO, J. L.; GARCIA, M.; BASTOS, P. S.; MOURÃO, M. A. F.; BOHLAND, E. Ocorrência da artrite encefalite caprina no Estado de São Paulo - Brasil. Arquivos da Escola de Medicina Veterinária da Universidade Federal da Bahia, v.16, n.1, p.60-6, 1993.

12 - EAST, N. E. Caprine arthritis encephalitis. In: SMITH, B. P., Large animal internal medicine. Philadelphia: Mosbi, 1990. p.1147-8.

13 - EAST, N. E.; ROWE, J. D.; MADEWEL, B. R.; FLOYD, K. Serologic prevalence of caprine arthritis-encephalitis virus in California goat dairies. Journal of American Veterinary Medical Association, v.190, n.2, p.182-6, 1987.

14 - FERnANDES, M. A. Artrite encefalite caprina. Contribuição para o estudo epidemiológico em rebanhos leiteiros criados no Estado de São Paulo. São Paulo,1997, 83p. Dissertação (Mestrado) - Faculdade de Medicina Veterinária e Zootecnia. Universidade de São Paulo.

15 - FITERMAN I. R.; GILLET, T. Documento de informação e constatação da CAEV na Bahia e proposta para levantamento de dados, identificação e profilaxia de novos rebanhos acometidos por esta enfermidade. Salvador: Secretaria da Agricultura do Estado da Bahia. Instituto Bahiano de Desenvolvimento Florestal e Recursos Naturais. Fundação CEPA, 1988. 5p. (Mimeografado)

16 - GARCIA, M.; GALHARDO, M.; ARAUJO, W. P.; D'ANGELINO, J. L.; BASTOS, P. S.; ROSSINI, A. J. Caprine arthritis-encephalitis (CAE). Occurrence of positive sera in goats raised in Brazil. Tropical Animal Health and Production, v.24, n.3, p.164, 1992.

17 - HARKISS, G. D.; WATT, N. J. Lentivirus infections and their detection. Goat Veterinary Society Journal, v.11, n.1, p. 19-25, 1990.

18 - HÖTZEL, I.; BASTOS, E. S.; RAVAZOLLO, A. P.; PIZZOL, M. D.; GOMES, M. Caprine arthritis encephalitis virus: isolation and identification in Rio Grande do Sul, Brazil. Brazilian Journal Medicine Biology Research, v.11, n.26, p.1175-9, 1993.

19 - LERONDELLE, C.; FLEURY, C.; VIALARD, J. La glande mammaire: organe cible de l'infection par le virus de l'arthrite et de l'encéphalite caprine. Annales de Recherches Veterinaires, v.20, n.1, p.57-63, 1989.

20 - MOOJEN. V.; CORREA SOARES, H.; RAVAZZOLO, A. P.; DAL PIZZOL, M.; GOMES, M. Evidência de infecção pelo lentivirus (maedi-visna/ artrite-encefalite caprina) em caprinos no Rio Grande do Sul, Brasil (Comunicação Científica). Arquivos da Faculdade de Veterinária UFRGS, v.14, p.77-8, 1986 .

21 - NARAYAN, O.; CORK, L. C. Lentiviral diseases of sheep and goats: chronic pneumonia leukoencephalomyelitis and arthritis. Reviews of Infectious Diseases, v.7, n.1, p.8998,1985 .

22 - NARAYAN, O.; CORK, L. C. Caprine arthritis-encephalitis virus. In: DINTER, Z; MOREIN, B. Virus infections of ruminants. Amsterdam: Elsevier, 1990. p. 441-52.
23 - NARAYAN, O.; WOLINSKY, J. S.; CLEMENTS, J. E.; STRANDBERG; GRIFFIN, D. E.; CORK, L. C. Slow virus replication: the role of macrophages in the persistence and expression of visna virus of sheep and goats. Journal of General Virology, v.59, n.2, p.345-56, 1982.

24 - OLIVER, R. E.; ADAMS, D. S.; GORHAM, J. R.; JULIAN, A. F.; MCNIVEN, R. A.; MUIR, J. Isolation of caprine arthritis-encephalitis virus from a goat. New Zealand Veterinary Journal, v.30, n.10, p.147-9, 1982 .

25 - PAAPE, M. J.; CAPUCO, A. V. Cellular defense mechanisms in the udder and lactation of goats. Journal of Animal Science, v.75, n.2, p.556-65, 1997.

26 - PINHEIRO, R. R.; ALVES, F. S. F.; GIRÃO, E. S.; MEDEIROS, L.PA.; GIRÃO, R. N. Presença da artrite encefalite caprina a vírus (CAEV) em Teresina-Piauí. In: CONGRESSO BRASILEIRO DE MEDICINA VETERINÁRIA, 24, Goiânia, 1996. Anais. Goiânia: Sociedade Goiânia de Veterinária, 1996. p.161.

27 - ROBINSON, W. F.; ELLIS, T. M. Caprine arthritis-encephalitis virus infection: from recognition to eradication. Australian Veterinary Journal, v.63, n.8, p. 237-41, 1986.

28 - ROWE, J. D.; EAST, N. E.; FRANTI, C. E.; THURMOND, M. C.; PEDERSEN, N. C.; THEILEN, G. $\mathrm{H}$. Risk factors associated with the incidence of seroconversion to caprine arthritis-encephalitis virus in goats on California dairies. American Journal of Veterinary Research, v.53, n.12, p.2396-403, 1992.

29 - ROWE, J. D.; EAST, N. E.; THURMOND, M. C.; FRANTI, C. E.; PEDERSEN, N. C. Cohort study of natural transmission and two methods for control of caprine arthritisencephalitis virus infection in goats on a California dairy. American Journal of Veterinary Research, v.53, n.12, p.2386-95, 1992.

30 - RYAN, D. P.; GREENWOOD, P. L.; NICHOLLS, P. J. Effect of caprine arthritis-encephalitis virus infection on milk cell count and $\mathrm{N}$-acetyl-b-glucosaminidase activity in dairy goats. Journal of Dairy Research, v.60, n.3, p.299-306, 1993.

31 - SARAIVA NETO, A. O.; BIRGEL, E. H.; CASTRO, R. S. AEC soroprevalência em Pernambuco. . In: CONGRESSO BRASILEIRO DE MEDICINA VETERINÁRIA, 23, Olinda, 1994. Anais. Olinda: Sociedade Pernambucana de Medicina Veterinária, 1994. p.100.

32 - SERAKIDES, R.; NUNES, V. A.; PEREIRA, M. F. Estudo clínico, anatomopatológico e imuno-histoquímico de pulmões de cabras naturalmente infectadas pelo vírus da artrite encefalite caprina (CAE). Arquivo Brasileiro de Medicina Veterinária e Zootecnia, v.48, n.4, p.415-24, 1996.

33 - SMITH, M. C.; SHERMAN, D. M. Goat medicine. Philadelphia: Lea \& Febiger, 1994. p.73-9: Caprine arthritis encephalitis.

34 - WOODWARD, J. C.; GASKIN, C.; POULOS, P. W.; MACKAY, R. J.; BURRIDGE, M. J. Caprine arthritisencephalitis: clinicopathologic study. American Journal of Veterinary Research, v.43, n.12, p.2085-96, 1982. 